\title{
GELDANAMYCIN, A NEW ANTIBIOTIC
}

\author{
C. DeBoer, P. A. Meulman, R. J. Wnuk and D. H. Peterson \\ Research Laboratories, The Upjohn Company, \\ Kalamazoo, Michigan 49001, U.S.A.
}

(Received for publication August 3, 1970)

\begin{abstract}
A new crystalline antimicrobial compound, geldanamycin, has been discovered in the culture filtrates of Streptomyces hygroscopicus var. geldanus var. nova. Geldanamycin is moderately active in vitro against protozoa, bacteria and fungi. It is also active against $\mathrm{L}-1210$ and $\mathrm{KB}$ cells growing in culture and against the parasite Syphacia oblevata, in vivo. The fermentation, assay, chromatography and isolation as well as its biological and chemical properties were investigated. On the basis of its physical and chemical properties, geldanamycin is a complex molecule consisting of an unsaturated moiety attached to a quinone.
\end{abstract}

In the process of screening for substances which inhibit the growth and multiplication of protozoa, a new compound was isolated which was primarily active against Tetrahymena pyriformis and Crithidia fasciculata. This substance was produced in submerged culture by a new actinomycete found in a Kalamazoo soil and was identified as Streptomyces hygroscopicus var. geldanus var. nova (UC-5208).*

\section{Production of Geldanamycin}

The inoculum for seed flasks was obtained from spore preparations of the culture maintained in sterile soil or in liquid $\mathrm{N}_{2}$. The culture was incubated at $28^{\circ} \mathrm{C}$ for 48 hours in a $1 \%$ glucose monohydrate, $1 \%$ peptone (Difco) and $\frac{1}{4} \%$ yeast extract (Difco) medium.

A $5 \%$ vegetative seed was used to inoculate the fermentation medium consisting of glucose monohydrate ( $40 \mathrm{~g} /$ liter), peptone ( $2 \frac{1}{2} \mathrm{~g} /$ liter), tryptone $\left(2 \frac{1}{2} \mathrm{~g} /\right.$ liter), yeast extract ( $2 \frac{1}{2} \mathrm{~g} /$ liter), Gerber's oatmeal ( $5 \mathrm{~g} /$ liter), and Brer Rabbit molasses (10 ml/liter) (Penick and Ford-Gold Label). Prior to sterilization $\left(121^{\circ} \mathrm{C}\right.$ for 20 minutes) the $\mathrm{pH}$ was adjusted to 7.0 . All shaken flask fermentations were run in $500 \mathrm{ml}$ Erlenmeyer flasks with $100 \mathrm{ml}$ of medium and incubated at $28^{\circ} \mathrm{C}$ on a Gump rotary shaker operating at $250 \mathrm{rev} / \mathrm{min}$. with a $6.35-\mathrm{cm}(2.5 \mathrm{in}$.) stroke.

Table 1 shows a typical fermentation $\mathrm{pH}$ and antibiotic titer pattern produced by $S$. hygroscopicus

Table 1. Fermentation titer and $\mathrm{pH}$ pattern of $S$. hygroscopicus var. geldanus var. nova

\begin{tabular}{c|c|c}
\hline Hours & $\mathrm{pH}$ & $\begin{array}{c}\text { Assay } \\
\text { (biounits) }\end{array}$ \\
\hline 24 & 7.3 & 2 \\
48 & 7.0 & 16 \\
72 & 6.9 & 64 \\
96 & 6.65 & 96 \\
\hline
\end{tabular}
var. geldanus. Peak yields of $c a .100$ biounits $/ \mathrm{ml}$ were obtained in $4 \sim 5$ days. Continuation of the fermentation longer than 5 days did not increase the titer.

\footnotetext{
* This organism has been characterized by A. Dierz of these laboratories.
} 


\section{Assay Procedure}

The antibiotic concentrations were determined using a standard disc-plate agar diffusion assay. Dilutions were made with a $\mathrm{pH} 6.0$ phosphate buffer. Samples $(0.08 \mathrm{ml})$ were applied to $12.7 \mathrm{~mm}$ paper discs (Schleicher and Schuel) and assayed against Tetrahymena pyriformis growing in $1 \%$ proteose-peptone \#3 (Difco), $1 \%$ glucose monohydrate, $0.1 \%$ yeastolate medium (Difco), and $0.4 \%$ Ionagar No. 2 (Colab). The diameter of zones of growth inhibition were measured to the nearest $\mathrm{mm}$ after a 42 hour incubation at $26^{\circ} \mathrm{C}$. The antibiotic activity was expressed in biounits. One biounit equals the amount of antibiotic necessary to produce a $20 \mathrm{~mm}$ zone of inhibition under standard conditions. One mg of crystalline geldanamycin is the equivalent of $240 \sim 350$ biounits.

\section{Chromatography}

Paper: Geldanamycin was differentiated from other antibiotics by descending paper-chromatography. Approximately $100 \mathrm{mcg}$ of geldanamycin was spotted on Whatman $\$ 1$ filter paper and developed without equilibration in solvent vapors. The antibiotic was detected with bioautography on trays of agar seeded with $T$. pyriformis in a medium consisting of $1 \%$ glucose monohydrate, $1 \%$ proteose-peptone \#3, $0.1 \%$ yeastolate, $0.4 \%$ Ionagar (Oxoid) and distilled water. A $20 \%$ inoculum was used with a $35 \sim 45 \%$ light transmission at $530 \mathrm{~m} \mu$ on a Model 401 Lumetron Colorimeter. Trays were incubated at $26^{\circ} \mathrm{C}$ for 42 hours before reading.

Bioautographs of the culture filtrate revealed two components which moved differently in three solvent systems as shown in Fig. 1.

Fig. 1. Tetrahymena pyriformis bioautograph pattern of geldanamycin. Solvent systems: I, 1-butanol-water (84: 16) plus $2 \% p$-toluene-sulfonic acid, developed 64 hours; II, $0.075 \mathrm{~N}$ ammonium hydroxide saturated with methyl isobutyl ketone, developed 5 hours; III, paper strip is equilibrated at $25^{\circ} \mathrm{C}$ in vapor form mixed solvent composed of benzene-methanol-water $(1: 1: 2)$ and developed in upper phase 5 hours.

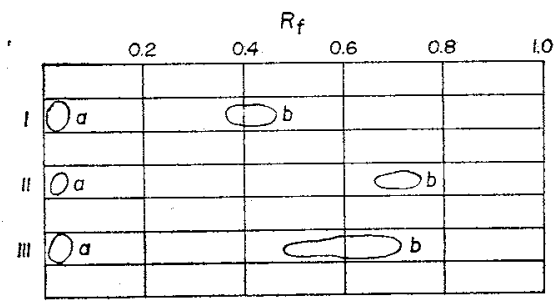

The major component listed as B on the papergram was extracted, crystallized and designated as geldanamycin.

Thin-Layer: On Silica Gel H (E. Merck, A. G., Darmstadt, Germany) tlc plates at neutral $\mathrm{pH}$ and a solvent system of $9: 1$ or $9.5: 0.5$ chloroform:methanol, the Rf value of geldanamycin was determined to be 0.56 . The antibiotic was detected by noting the yellow color or by exposure to U. V. light.

Golumn: As an alternate method of purification, Silica gel G7734 (E. Merck, A. G. Darmstadt, Germany) was used as the matrix and the same solvent system employed as used in thin-layer chromatography.

\section{Isolation and Purification of Geldanamycin}

Two-hundred-forty liters of cultured medium was filtered and the filtrate extracted with 3-133 liter-portions of $n$-butanol. The combined extracts were concentrated by vacuum at $40^{\circ} \mathrm{C}$ to a volume of 5.5 liters. At this point crude crystals 
of approximately $35 \%$ purity formed, and were separated by filtration: weight of dried crystals (I) was $187.5 \mathrm{~g}$; m.p. $257 \sim 261^{\circ} \mathrm{C}$, assay $120 \mathrm{u} / \mathrm{mg} .47 .9 \mathrm{~g}$ of I was dissolved in $900 \mathrm{ml}$ of boiling chloroform and filtered. The filtrate (II) contained the major part of geldanamycin and was retained for further treatment. The insoluble material was extracted twice using $16 \mathrm{ml}$ of methanol and $50 \mathrm{ml}$ of chloroform each time and filtered (III and IV). The soluble fractions II, III and IV were combined and the solvents evaporated, leaving $32.5 \mathrm{~g}$ of solids ( $\mathrm{V}$ ). V was dissolved in $700 \mathrm{ml}$ of boiling chloroform and the solution concentrated to $375 \mathrm{ml}$ under nitrogen at $60^{\circ} \mathrm{C}$. Yellow crystals began to form at this point and $28 \mathrm{ml}$ of diethylether was added to complete the crystallization $\left(6.94 \mathrm{~g}\right.$, m.p. $252^{\circ} \sim 255^{\circ} \mathrm{C}$ ). Recrystallization did not change the melting point. All melting points were determined on a KOFFLER block and corrected.

\section{Physical and Chemical Properties of Geldanamycin}

Geldanamycin is soluble in alcohols, aliphatic chlorinated solvents, particularly chloroform, and to a lesser extent, acetone, benzene and ethyl acetate, but only very slightly in water. In solution, it decomposes rather readily with acid, base or heat in the presence of oxygen, but as a dry material it is stable.

The crystalline material forms: yellow needles, m.p. $252^{\circ} \sim 255^{\circ} \mathrm{C} ;[\alpha]_{\mathrm{D}}^{25^{\circ}}+55^{\circ}(c$,

Fig. 2. Mass spectrum of geldanamycin.

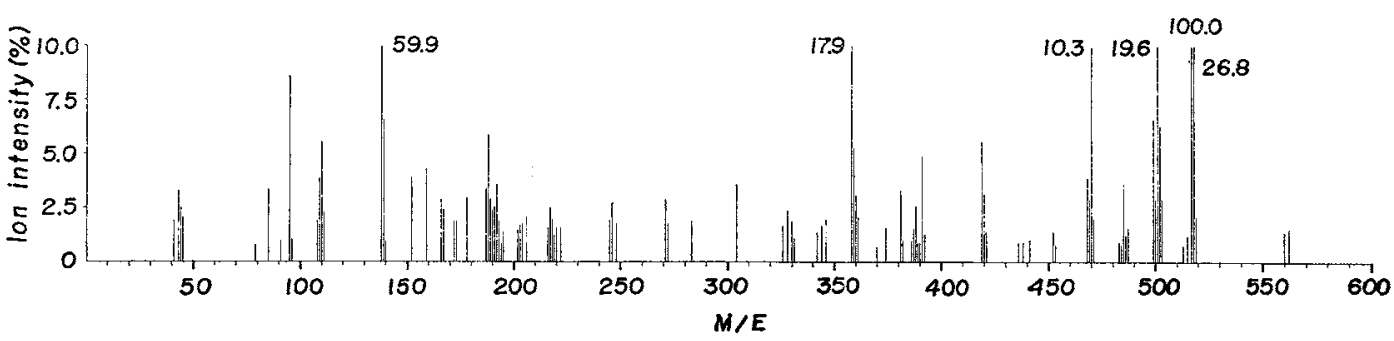

Fig. 3. Infrared absorption spectrum of geldanamycin (Nujol mull).

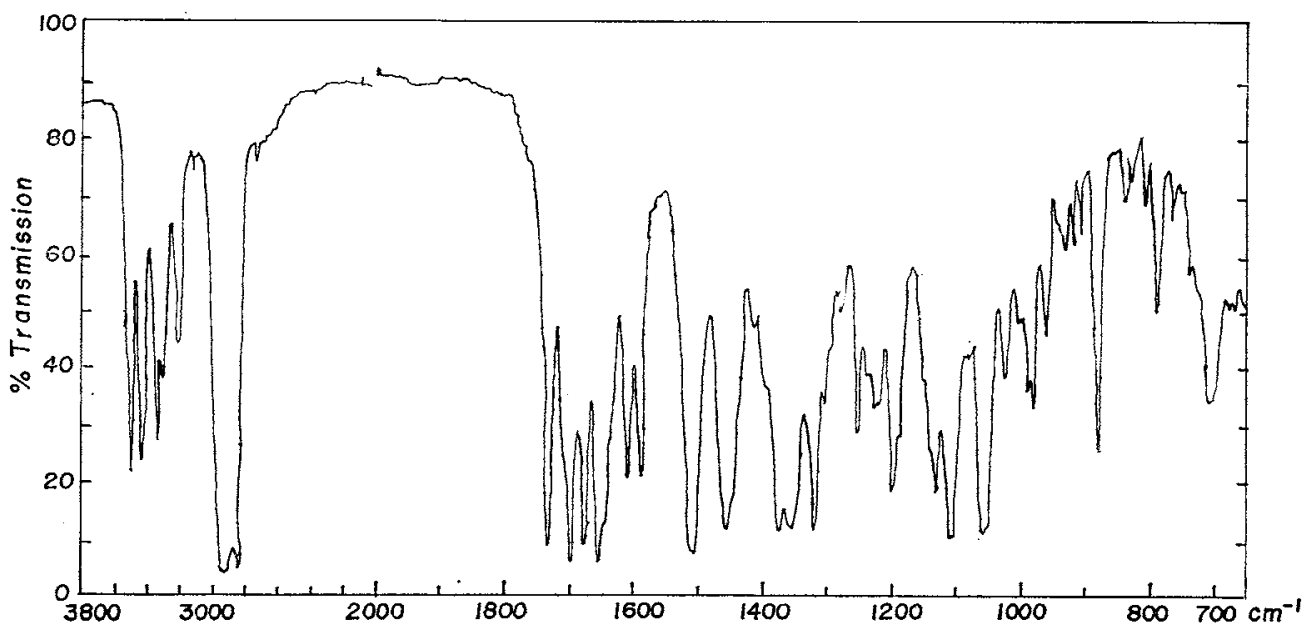


$0.638 \mathrm{CHCl}_{3}$ ); mass spectrometric analyses were performed on geldanamycin with a CEC-21-110B mass spectrometer incorporating a direct inlet probe. Most of the spectra were obtained by inserting the sample into the ion source at about $100^{\circ} \mathrm{C}$ and slowly raising the temperature until ions were obtained (Fig. 2); the mass spectrum of geldanamycin shows a large peak at 517 and weak peaks of about equal intensity at 560 and 562. Accurate mass measurements indicated that the peaks at 562, 560 and 517 corresponded to $\mathrm{C}_{29} \mathrm{H}_{42} \mathrm{~N}_{2} \mathrm{O}_{9}, \mathrm{C}_{29} \mathrm{H}_{40} \mathrm{~N}_{2} \mathrm{O}_{9}$ and $\mathrm{C}_{28} \mathrm{H}_{41} \mathrm{NO}_{8}$ respectively; the 560 and 562 peaks were initially interpreted as being separate real entities differing by two hydrogen atoms, (i.e., a double bond, ketone vs. alcohol, etc.). Since other spectroscopic and chemical evidence suggest that geldanamycin contains a quinone moiety, and since some quinones yield apparent $\mathrm{M}^{+}+2$ peaks in the ion source of the mass spectrometer, ${ }^{2,3,4)}$ a logical choice for the empirical formula of geldanamycin is $\mathrm{C}_{29} \mathrm{H}_{40} \mathrm{~N}_{2} \mathrm{O}_{9}$ at mass 560 . The peak at mass 517 , corresponding to $\mathrm{C}_{28} \mathrm{H}_{39} \mathrm{NO}_{8}$ represents HOCN loss from the 560 peak; elemental analysis for M.W. 560: Calcd. for $\mathrm{C}_{29} \mathrm{H}_{40} \mathrm{~N}_{2} \mathrm{O}_{9}$ : C 61.69, $\mathrm{H}$ 7.16, $\mathrm{N}$ 5.15, O 25.62. Found: C

Fig. 4. Ultraviolet absorption spectrum of geldanamycin.

62.13, H 7.26, N 5.00, O 25.68; equivalent weight titrates as a monobasic acid having a neutral equivalent of 560 ; I.R. absorption spectrum was obtained from a Nujol mull (Perkin-Elmer model 421 spectrophotometer). The spectrum has characteristic bands at 3510, 3445, 3350,

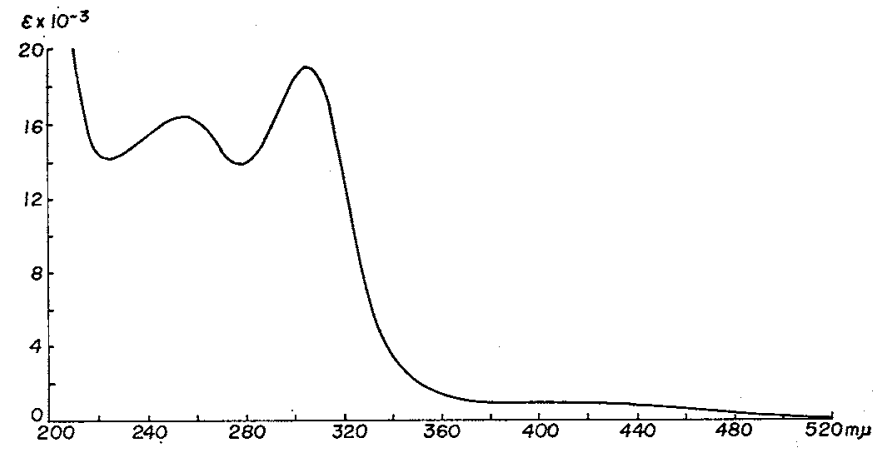

Fig. 5. N.M.R. spectrum of geldanamycin.

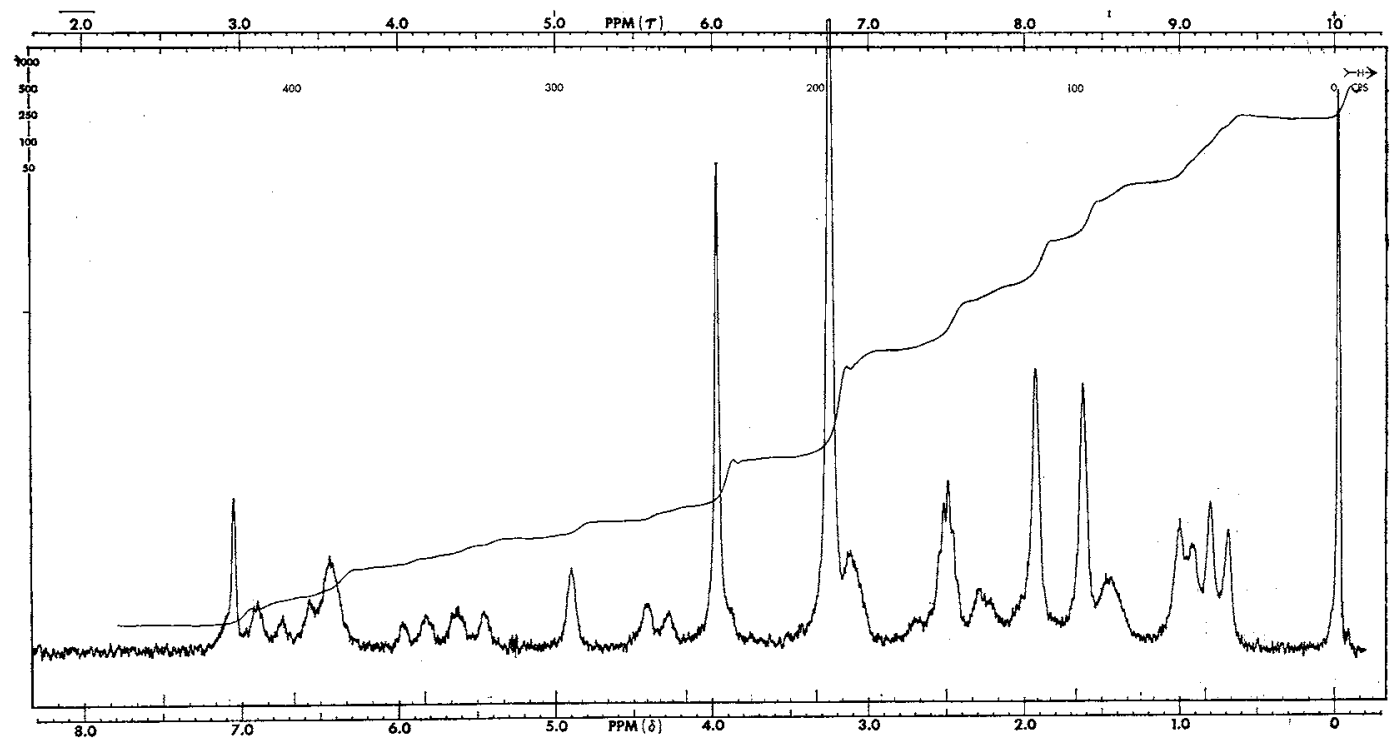


$3315,1734,1700,1676,1655,1635,1608,1590,1510,1108$ and $1056 \mathrm{~cm}^{-1}$. These peaks in conjunction with other physical data are consistent with alcohol, ether, an Ocarbamate and a quinone group (see Fig. 3); U. V. spectrum (Fig. 4) of geldanamycin was obtained from a methanol solution using a Cary Model 15 spectrophotometer. Maxima occur at $255 \mathrm{~m} \mu(\varepsilon=16,350), 304 \mathrm{~m} \mu(\varepsilon=19,300)$ and a broad, weak shoulder near $400 \mathrm{~m} \mu(\varepsilon=980)$; the N.M.R. spectrum (Fig. 5) was measured on a solution of geldanamycin in deuterated dimethylsulfoxide using a Varian A-60A spectrometer. The multiplet at $\delta 2.52$ is attributed to residual protons in the solvent; the N.M.R. spectrum showed absorptions for 40 hydrogens including three methoxy groups and five additional $\mathrm{C}-$ methyl groups :

Acetylation

To $1 \mathrm{~g}$ of purified geldanamycin dissolved in $10 \mathrm{ml}$ of pyridine was added $10 \mathrm{ml}$ of acetic anhydride. After stirring for 6 hours the preparation was allowed to stand at room temperature overnight. The solid mass obtained atter concentration under vacuum at $40^{\circ} \mathrm{C}$ was chromatographed over silica gel G \#7734 (E. Merck A.G.) using a mixture of $95 \%$ chloroform and $5 \%$ methanol. The eluates were concentrated to dryness in vacuo and the material crystallized and recrystallized from a chloroform solution to which $40 \%$ methanol was added. Light yellow crystals (prisms) of the monoacetate m.p. $206^{\circ} \sim 209^{\circ} \mathrm{C}$ were obtained and indicated a compound of molecular weight 602.28 by mass spectrometry. The acetate was biologically inactive at $2 \mathrm{mg} / \mathrm{ml}$ against $T$. pyriformis.

Hydrogenation

Using $\mathrm{PtO}_{2}, 2.4$ moles of hydrogen were consumed by geldanamycin and a colorless compound resulted which turned dark rapidly in the presence of air, indicating a hydroquinone had been formed.

Methyl ether derivative

With diazomethane the hydrogenated compound above produced a derivative which did not discolor in the presence of air and showed the loss methanol or water and the introduction of one additional methyl group by mass spectrometry.

\section{In vitro spectrum}

The antibacterial spectrum was determined by two-fold dilution endpoints in Bacto Brain Heart Infusion (Difco) broth. The growth inhibition of the protozoa $(C$. fasciculata and $T$. pyriformis) was performed in the same manner in a medium consisting of $1 \%$ glucose, $1 \%$ Bacto ProTable 2. Antimicrobial spectrum of geldanamycin

\begin{tabular}{l|r}
\hline \multicolumn{1}{c|}{ Test organism } & MIC* \\
$\mu \mathrm{g} / \mathrm{ml}$
\end{tabular}

* MIC : Minimal inhibitory concentration

* Upjohn culture collection number

*** Spectrum was run in Difco's Brain Heart Infusion Broth with the exception of $C$. fasciculata and $T$. pyriformis (see text) tease-Peptone $\# 3$ (Difco), and $0.1 \%$ yeastolate (Difco). 
A 16-hour growth $\left(37^{\circ} \mathrm{C}\right)$ of each bacterial test organism was used as inoculum in a final concentration of $1: 40,000$. The inoculated broth was incubated for 16 hours at $37^{\circ} \mathrm{C}$, at which time the minimum inhibitory concentrations were recorded.

The inhibition of the protozoa was measured in the same way as the bacteria except that they were incubated at $26^{\circ} \mathrm{C}$ for 48 hours, diluted to a final concentration of $1: 1,000$ for inoculation, and incubated for 48 hours $\left(26^{\circ} \mathrm{C}\right)$. The results are given in Table 2.

It has demonstrated activity against several fungal plant pathogens, viz; Alternaria, Pythium, Botrytis and Penicillium ( $<500 \mathrm{ppm}$ ).

Geldanamycin is extremely active against $\mathrm{KB}$ cells $(<0.001 \mathrm{mcg} / \mathrm{ml})$ and L.1210 cells $(<0.002 \mathrm{mcg} / \mathrm{ml})$. The $\mathrm{ID}_{50}$ indicates that geldanamycin is approximately $2 \sim 4$ times as active as cytosine arabinoside ${ }^{4)}$.

Geldanamycin is inactive at $0.5 \mathrm{mg} / \mathrm{ml}$ against Coxsackie A-21, Parainfluenza type 3, and Herpes simplex viruses, by an agar diffusion test.

In vivo Activity

In mice, geldanamycin was orally active against the parasite Syphacia oblevata at $0.5 \mathrm{mg} / \mathrm{mouse} /$ day for 4 days, but inactive against Plasmodium berghei when given at $20 \mathrm{mg} / \mathrm{kg}$ (SQ). In a poultry coccidiostat screen it showed partial control at a $0.0125 \%$ concentration in the diet while in dogs it showed only slight anthelminthic activity when given orally.

The acute oral toxicity in rats was determined to be $2,500 \sim 5,000 \mathrm{mg} / \mathrm{kg}$ while the I.P. $\mathrm{LD}_{50}$ in mice was estimated at $1 \mathrm{mg} / \mathrm{kg}$, suggesting a toxic compound which is poorly absorbed.

\section{Acknowledgements}

The authors wish to thank the following contributors for assistance in the work described in this paper: H. H. Buskirk, K. M. Calhoun, F. L. Dorbin, J. A. Fox, R. E. Kohls, C. Lewis, M. K. Morgan, H. E. Renis, D. Rohrstaff, D. Van Overloop, and R. N. Weaver.

\section{References}

1) Budzikiewicz, H.; C. Duerassi \& D. Williams: Mass Spectrometry of Organic Compounds. p. 118, Holden-Day, San Francisco, 1967

2) Alpin, R. T. \& W. T. PIKE: Mass spectra of 1,4 dihydroxy-benzenes and $p$-benzoquinones: Quinol-quinne interconversion in the heated inlet system of mass spectrometer. Chem. \& Ind. $1966: 2009,1966$

3) Das, B. C.: M. Lounasmad, C. Tendille \& E. Lederer: Mass spectrometry of plastoquinones. The structure of plastoquinones B, C and D. Biochem. Biophys. Res. Comm. $21: 318 \sim 322$, 1965

4) Sмгtн, C.G.; H.H. Buskink \& W.L. Lummis: Effect of arabino furanosyl uracil on the cytotoxicity of arabino furanosylcytosine in PPLO contaminated cell cultures. Proc. Amer. Ass. Cancer Res. $6: 60,1965$ 